This document is published in:

Mechanics of Materials, 2013, 62, 1-13. Doi:

http://dx.doi.org/10.1016/j.mechmat.2013.03.002.

(C) Elsevier 


\title{
Dynamic tensile necking: Influence of specimen geometry and boundary conditions
}

\author{
S. Osovski ${ }^{\mathrm{a}, *}$, D. Rittel ${ }^{\mathrm{a}, \mathrm{b}}$, J.A. Rodríguez-Martínez ${ }^{\mathrm{b}}$, R. Zaera ${ }^{\mathrm{b}}$ \\ ${ }^{\text {a }}$ Faculty of Mechanical Engineering, Technion, 32000 Haifa, Israel \\ ${ }^{\mathrm{b}}$ Department of Continuum Mechanics and Structural Analysis, University Carlos III of Madrid, 28911 Leganés, Madrid, Spain
}

Keywords:

Dynamic tensile testing

Necking

Wave propagation

Boundary conditions

\begin{abstract}
A B S T R A C T
This paper examines the effects of sample size and boundary conditions on the necking inception and development in dynamically stretched steel specimens. For that task, a coordinated systematic experimental-numerical work on the dynamic tensile test has been conducted. Experiments were performed using a tensile Kolsky apparatus for impact velocities ranging from 10 to $40 \mathrm{~m} / \mathrm{s}$. Three different sample-gauge lengths - 7, 30 and $50 \mathrm{~mm}-$ were considered for which the cross section diameter is $3.4 \mathrm{~mm}$. The experiments revealed that the specimens' ductility to fracture depends on strain rate and sample length. Furthermore it was observed that, for those specimens having gauge lengths of 30 and $50 \mathrm{~mm}$, the necking location varies with impact velocity. Numerical simulations of the dynamic tensile tests were carried out in order to characterize the dynamics of neck inception and development. For each specimen calculated, three types of boundary conditions were used, all of which match the experimentally measured strain-rate. It was pointed out that, while boundary conditions hardly affect the calculated stress-strain characteristics, they strongly affect the wave propagation dynamics in the specimen thus dictating the necking location.
\end{abstract}

\section{Introduction}

Different industrial sectors such as the automotive (Rusinek et al., 2008; Kazanci and Bathe, 2012), aeronautical (Karagiozova and Mines, 2007; Varas et al., 2009), naval (Wang et al., 2008; Ehlers, 2010) or manufacturing (Miguélez et al., 2009; Verleysen et al., 2011) require quick and accurate modeling of systems to optimize design parameters, accounting for impact loads. The rapid progress in computational mechanics permits to simulate solids and structures undergoing high strain rates. One of the obstacles that may limit such simulations is the realistic modeling of the mechanical behavior of materials. Therefore reliable experimental data are needed to develop accurate constitutive models accounting for the influence

\footnotetext{
* Corresponding author. Tel.: +1 9402315153.

E-mail address: shmulo@gmail.com (S. Osovski).
}

of the loading rate on material deformation behavior. Extensive reviews of methods for dynamic testing have been published elsewhere (Lindholm, 1974; Field et al., 2004).

Among the dynamic tests, the uniaxial tensile is one of the most commonly used (after the compression test). The first detailed investigations on high-velocity tension impact tests are dated to the mid-20th century. At that time a number of investigators focused their attention on developing reliable experimental methodologies to capture the mechanical properties under rapid loading of different metals and alloys (Mann, 1936, 1937; Clark and Datwyler, 1938; Parker and Ferguson, 1942; Manjoine, 1944). The effect of velocity on the absorbed energy in the sample was demonstrated. In Mann's words (Mann, 1936) the experimental data "definitely showed that high velocity tests are essential to reveal the true dynamic properties of materials". This finding was a milestone in the investigation of dynamic behavior of materials. Moreover, the improvements in the tensile impact testing developed during this period 
served to identify some characteristic features of the dynamic tensile test, namely:

- There exists a correlation between fracture location and impact velocity. Under static (tensile) loading of a smooth specimen, failure is invariably located in the middle of the gauge, while under impact loading, sample failure may occur at a different location. This correlation was described as being sample-size dependent.

- There exists a material-dependent transition-velocity which defines the maximum energy absorbed by the sample and the maximum sample ductility in the dynamic tension test. This transition-velocity showed correlation with the impact-velocity which induces sample failure close to the impacted end.

Years later, Clark and co-workers shed additional light on previous findings in a series of celebrated papers (Duwez and Clark, 1947; Clark and Duwez, 1948, 1950; Clark and Wood, 1950). In these studies, the one-dimensional theory of plastic waves propagation developed by Karman and others (Karman, 1942; Rakhmatulin, 1945; White and Griffis, 1947; Karman and Duwez, 1950) was taken into account for the first time in interpreting the experimental results. Based on the processes of reflection and interaction of strain waves taking place in the sample during impact, the principles of strain wave propagation provided an explanation to the interplay between fracture location and impact velocity (Clark and Duwez, 1948). In addition, the aforementioned transition-velocity, from this point on renamed as Critical Impact Velocity (CIV), was thus considered as a material property (Clark and Wood, 1950). Further investigations presented data to show that it is necessary to maintain a certain ratio of the specimen's length to diameter in order to clearly reveal the CIV (Clark and Wood, 1950). Since the size of the neck is rather independent of the impact velocity and approximately equal to the sample diameter, the gauge length of the specimen must be much longer than the length of the necked region to allow for strain wave propagation phenomena within the sample. This is usually considered as an undesirable disturbance effect, and the use of short specimens in impact tensile testing has become a common experimental practice (Simmons et al., 1961; Lindholm, 1974; Bottet et al., 1969). Short samples reduce inertial effects and the strain rate can be assumed to remain uniform and constant throughout the test duration (Chiddister and Malvern, 1963), which in turn facilitates the analysis and interpretation of the experimental results. This practice led to important advances in the mechanical characterization of materials at high strain rates. However, the widespread use of short samples has set aside further research on the interaction between wave disturbances and necking inception. Especially, the role played by strain wave propagation on the fracture location was hardly investigated during the last decades.

However, further advances in understanding the relationship between strain wave propagation and necking inception were made with the advent of computational mechanics. For example, Knoche and Needleman,
(1993) analyzed the effect of sample size on the ductility of round bar tensile samples using finite element simulations. They pointed out the non-linear relationship between inertia and necking strain, concluding that "material inertia introduces a length scale so that for fixed imposed strain rate, specimen ductility is a function of specimen size". These authors investigated the dependence of the necking location on the sample size. Later, $\mathrm{Hu}$ and Daehn (1996) carried out numerical simulations of uniaxial extension of linear specimens and rings. The former configuration represents the regular tensile impact test in which wave propagation occurs, while the latter is free of wave disturbances due to the symmetry of the problem. They found that as the test velocity increases, the ductility of the linear specimens increases first, then drops rapidly once the CIV is reached. By contrast, the ductility of the expanded rings increased continuously with velocity, virtually without limits. The numerical results were consistent with experimental observations and provided further verification to the role played by the strain waves in limiting the sample ductility.

During the last decade, one should note the works of Klepaczko and co-workers (Rusinek and Klepaczko, 1999; Rusinek and Klepaczko, 2003; Klepaczko, 2005; Rusinek et al., 2005; Klepaczko, 2007), where extensive numerical analyses of tensile impact tests over wide ranges of impact velocities were reported for different materials. Inertia and scale effects on necking inception were successfully captured and the mechanisms which determine the fracture location of the sample were convincingly addressed. Furthermore, the authors revisited the former definition of the CIV derived by Karman under isothermal conditions of deformation (Karman, 1942) and extended it to the adiabatic case for strain, rate and temperature dependent materials (Klepaczko, 2005, 2007).

At this point one may summarize the main results discussed in the previous paragraphs as follows:

- The dynamic tensile ductility is size dependent. The sample elongation recorded from a tensile test cannot be treated as an indicator of the material ductility since it varies with the sample size.

- In the absence of wave disturbances, the tensile ductility of materials increases continuously with the loading rate as a consequence of the inertial resistance to motion. This is the intrinsic material response. Some particular cases in which this statement is not verified can be found in the literature. These exceptions are commonly tied to unusual material behaviors caused by specific microstructures, e.g. (Picu, 2004; Zhang et al., 2004; Benallal et al., 2008; Vadillo et al., 2012).

- In the presence of wave disturbances, the anticipated increase in tensile ductility with loading rate is limited by the strain gradients generated in the material. Once the CIV is exceeded, the tensile ductility decreases. In this situation, commonly reported in experimental works, the stress-strain behavior cannot be regarded as the intrinsic material behavior, but rather as the consequence of the specific initial and boundary conditions of the problem addressed. 
As mentioned above, progress in numerical modeling has been achieved while experimental techniques have progressed in parallel as well. However, there are still very few examples of coordinated systematic experimentalnumerical work on the dynamic tensile test, and this work is precisely of this nature. The following points, that are deemed to need further investigations, are therefore addressed:

- What is the relationship, if any, between the sample vs. material ductility?

- Is there an optimal specimen aspect ratio, and what, if at all, can be learnt from other specimen sizes?

- When numerical simulations of the experiments are carried out to extract additional information on the test, what are the proper boundary conditions, or more generally how do boundary conditions affect the calculated results?

- Last but not least, is the neck location dictated by statistically located geometrical imperfections, or is it a fully deterministic process that can be predicted?

\section{Experimental tests}

\subsection{Material and specimens}

The material of this study is a hardened 17-4 PH steel, supplied as $12.7 \mathrm{~mm}$ diameter bar, and tested in the as-received condition. This material is a high-strength fully martensitic steel with additional strengthening due to precipitation. Dynamic tensile cylindrical specimens with end threads were machined from the bar. The specimens' dimensions are shown in Fig. 1. A large number of specimens, in excess of 25 , were actually tested but a total of 10 specimens will be mentioned here, for which the tests were considered as successful (simultaneous full recording strain pulses and imaging). For those specimens, the gauge lengths ( $L$ in Fig. 1) were 7, 30 and $50 \mathrm{~mm}$, with a diameter of $3.4 \mathrm{~mm}$. In addition, dynamic compression cylinders were machined from the same 17-4 PH bar, with a diameter and length of $6 \mathrm{~mm}$. Those specimens were used to determine the dynamic compressive behavior of $\mathrm{PH}$ steel.

\subsection{Dynamic tension and compression setups}

The dynamic tensile specimens were tested in a $12.7 \mathrm{~mm}$ diameter tensile Kolsky apparatus (made of hardened 17-4 PH-steel) in which the end of the incident bar is loaded by a $400 \mathrm{~mm}$ long gas-launched cylindrical impactor. A Cordin 530 high speed camera was synchronized with the incident bar signals to capture the evolution of the specimen and neck's geometry during the dynamic tensile tests. The tested impact velocities ranged from 10 to $40 \mathrm{~m} / \mathrm{s}$. Dynamic compression specimens were tested in a standard $12.7 \mathrm{~mm}$ diameter Kolsky apparatus made of hardened C300 maraging steel.

\section{Experimental results}

\subsection{Dynamic compression tests}

A total of 5 specimens were tested within the range of strain rates $2000 \mathrm{~s}^{-1}<\dot{\varepsilon}<8000 \mathrm{~s}^{-1}$. Typical true stressstrain curves for 17-4 PH steel at two strain rates are shown in Fig. 2. Note that in order to determine these curves, dynamic specimen equilibrium was verified for each sample, and corrections for wave dispersion were applied using a home-made program according to the procedure described by Lifshitz and Leber (1994). The results of those preliminary tests indicate that, in the investigated range of strain rates, the material flow stress is largely strain-rate independent with $\sigma_{y} \approx 1400 \mathrm{MPa}$ and minimal strain-hardening. Note that such a behavior is common to many commercial martensitic steels.

\subsection{Dynamic tension tests}

Table 1 summarizes the various specimen geometries, macroscopic strain-rates and structural failure strains of each specimen. The term structural failure strain is to be understood here as determined from the total specimen elongation at failure (fracture). For this, two complementary pieces of information were used: we compared the photographic records (with respect to the interframe time) to the experimentally recorded strain rate as a function of time. When the latter started to accelerate abruptly as the result

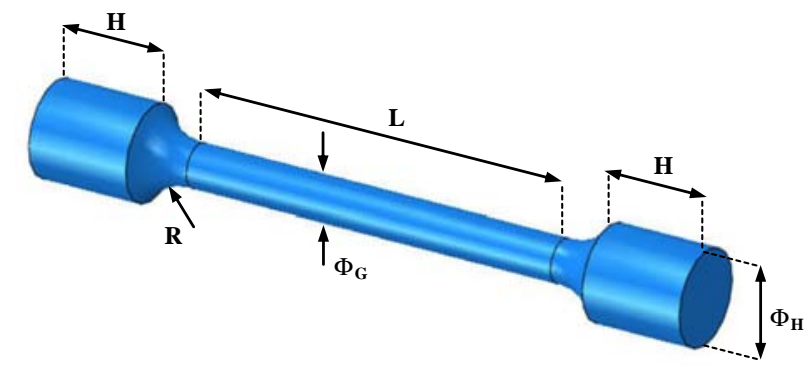

\begin{tabular}{ccc|c|c|c|c}
\hline \multicolumn{2}{c|}{$\mathbf{L}(\mathbf{m m})$} & $\mathbf{R}(\mathbf{m m})$ & $\mathbf{H}(\mathbf{m m})$ & $\Phi_{\mathbf{G}}(\mathbf{m m})$ & $\Phi_{\mathbf{H}}(\mathbf{m m})$ \\
\hline 7.0, & 30.0, & 50.0 & 4.6 & 8.0 & 3.4 & 7.4 \\
\hline
\end{tabular}

Fig. 1. Dynamic tensile specimen geometry and characteristic dimensions ( $\mathrm{mm})$. 


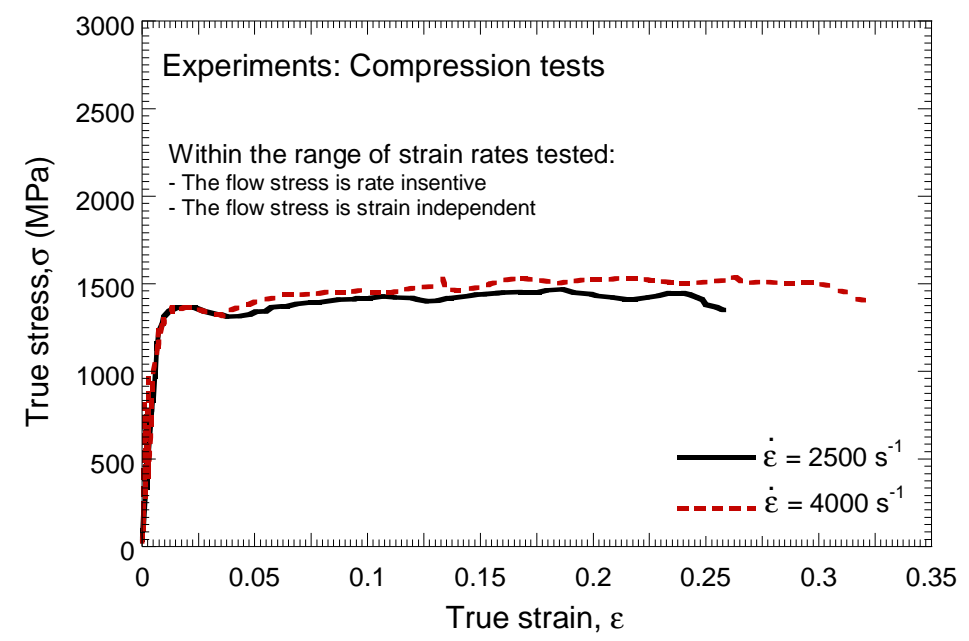

Fig. 2. Representative dynamic compression stress-strain curves for 17-4 PH steel.

Table 1

Summary of the experimental conditions and results.

\begin{tabular}{ccclll}
\hline Specimen & $L(\mathrm{~mm})$ & $\dot{\varepsilon}\left(\mathrm{s}^{-1}\right)$ & $V_{\text {in }}-V_{\text {out }}(\mathrm{m} / \mathrm{s})$ & Necking position (normalized by gauge length) & Structural strain to failure \\
\hline 1 & 7 & 2150 & 15 & 0.5 (middle) & 0.210 \\
2 & 7 & 3600 & 25 & 0.5 (middle) & Not measured \\
3 & 7 & 4000 & 28 & 0.5 (middle) & 0.170 \\
4 & 7 & 6000 & 42 & 0.5 (middle) & 0.200 \\
5 & 30 & 500 & 15 & 0.3 (opposite) & 0.070 \\
6 & 30 & 600 & 18 & 0.2 (opposite) & 0.080 \\
7 & 30 & 663 & 20 & 0.2 (opposite) & 0.085 \\
8 & 30 & 767 & 23 & 0.1 (opposite) & 0.070 \\
9 & 30 & 1067 & 32 & 0.8 (impacted) & 0.090 \\
10 & 50 & 380 & 19 & 0.1 (opposite) & 0.060 \\
\hline
\end{tabular}

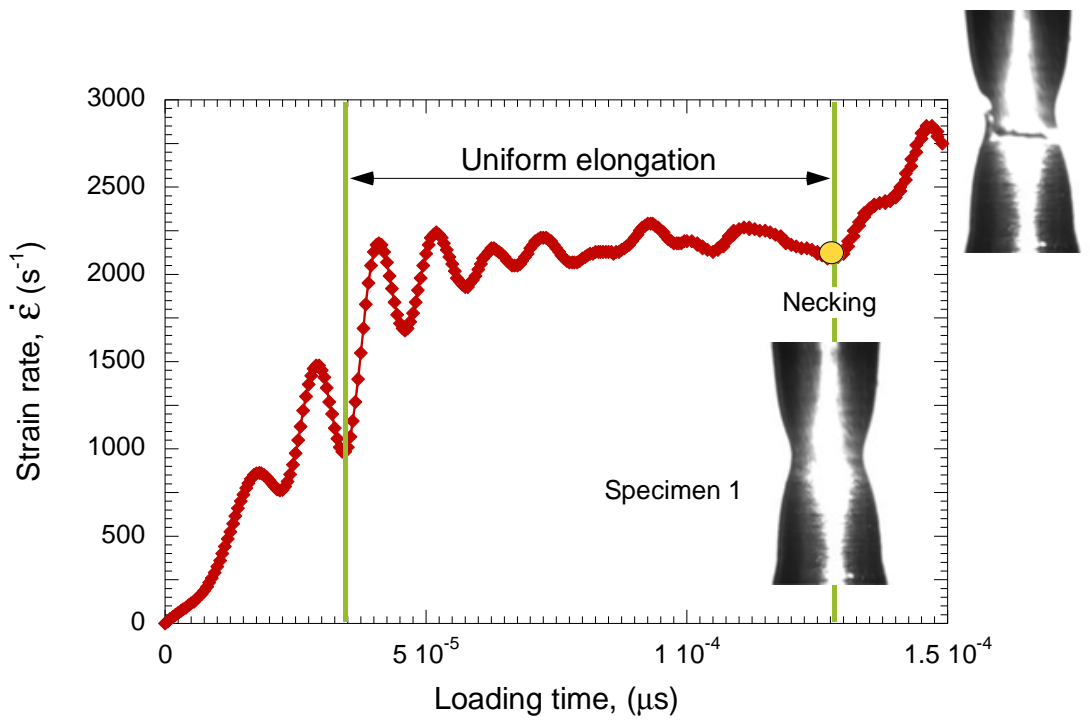

Fig. 3. Measured evolution of the strain rate (specimen 1). The onset of necking and subsequent fracture causes a sudden strain rate increase.

of necking and subsequent creation of a pair of free surfaces (fracture), we identified this discontinuity as the final fracture time, as shown in Fig. 3. This time was found to be well correlated with the photographic recording 


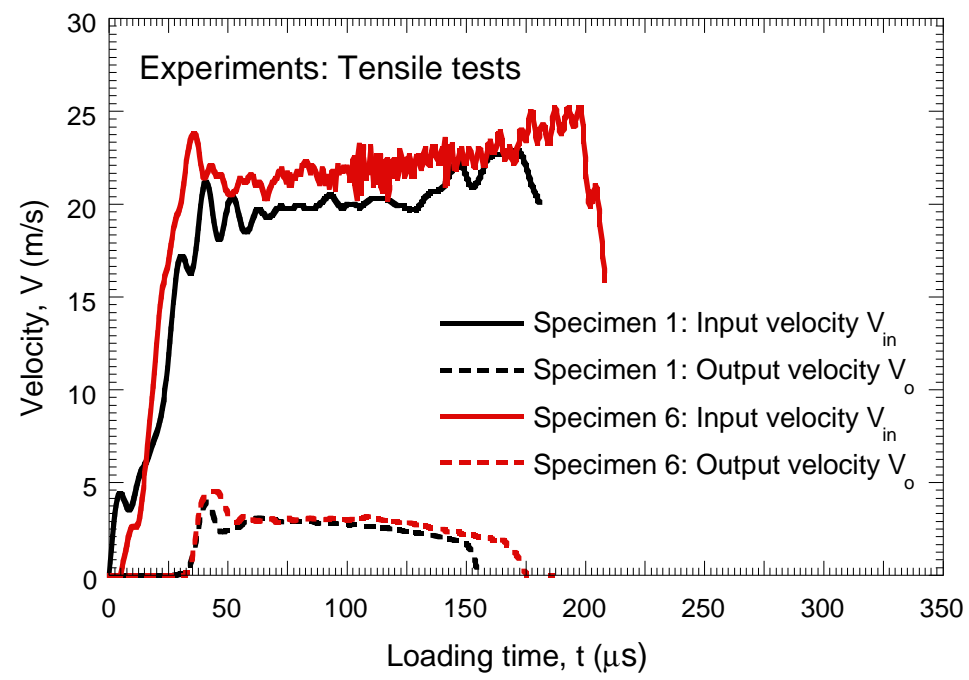

Fig. 4. Experimental boundary conditions recorded at input and output sides of the specimens $1\left(V_{\text {in }}-V_{\text {out }}=17 \mathrm{~m} / \mathrm{s}\right)$ and $6\left(V_{\text {in }}-V_{\text {out }}=18 \mathrm{~m} / \mathrm{s}\right)$.

within the limits of accuracy set by the framing rate. In this table, the strain-rate is the nominal one, defined as the difference between the end velocities of the specimen divided by its initial gauge length. Fig. 4 shows the time history of input (impacted side) and output (opposite side) velocities for two different tests. The net prescribed velocity is obtained by subtracting the transmitted from the incident velocity. The location of the neck is also specified in Table 1 , as it varies in the experiments from center of the specimen (middle) to the impacted or opposite side. One should note that the structural (sample) failure strain increases with the loading rate and decreases with the specimen length, which agrees with experimental, theoretical and numerical observations reported elsewhere (Chiddister and Malvern, 1963; Knoche and Needleman, 1993; Rusinek et al., 2005; Rodríguez-Martínez et al., in press).

Fig. 5 shows typical high speed sequences that were taken during the tests of specimens 3 and 6 . Here the load is applied on the right hand side of the specimen. One can note that for the shorter specimen, the neck develops at its center, whereas for the longer specimen the neck is clearly incepted close to the opposite side.

Next, the tensile stress-strain curves corresponding to specimens 3, 6 and 7 are shown in Fig. 6. One can observe that the specimen fails at different strain levels depending on the sample length and the loading rate (i.e. $\varepsilon \sim 0.17$ for specimen $3, \sim 0.08$ for specimen 6 and $\sim 0.085$ for specimen 7 ). Note that the flow stress level shown in Fig. 6 is rather similar to that obtained in compression. Additionally, one should note that the material shows rather limited strain and rate sensitivities, as observed for compression tests.

\section{Numerical modeling}

Numerical simulations of the dynamic tensile tests corresponding to specimens with 7 and $30 \mathrm{~mm}$ gauge length were carried out in order to characterize the dis- tribution and evolution of the plastic strain in the specimen, as well as the dynamics of the neck inception and development. The tensile specimen was modeled using ABAQUS/Explicit finite element software (Simulia, 2010). The mesh consists of four-node linear tetrahedron elements, C3D4 in ABAQUS notation. The gauge of the specimen has been meshed using elements with a characteristic edge length of $\sim 0.3 \mathrm{~mm}$. A mesh convergence study was performed; the time evolution of different critical output variables - namely stress, strain, necking strain and necking location - were compared against a measure of mesh density until the results converged satisfactorily. Concerning the boundary conditions, two different types of models we considered, as illustrated in Fig. 7. The first type - type $A$ - does not take into account for the sample holders. In the experimental system the specimen holders (with length denoted by $H$ in Fig. 1) are screwed into the bar so they can be considered as part of the bar rather than active part of the sample. The second kind of modeling - type $B$ - does take into account the sample holders. Type A will be used in the numerical computations, unless otherwise noted, as this configuration is considered closer to the experimental boundary conditions as will be demonstrated in forthcoming sections of this paper.

Since the experimental results showed that the material is reasonably strain-rate insensitive, as well as symmetrical in its response to both tension and compression, we assumed a representative mechanical behavior for this material according to the data shown in Fig. 2. These stress-strain characteristics were input in the model in tabular form, under the assumption of Huber-Mises plasticity. The elastic parameters were those characteristic of steel, $E=200 \mathrm{GPa}$ and $v=0.33$.

Finally, one should note that no initial imperfection was introduced in the model, such as to produce an unbiased location for the neck inception.

Fig. 8 shows, for specimen 3, the idealized velocity curves used in the numerical simulations as boundary con- 


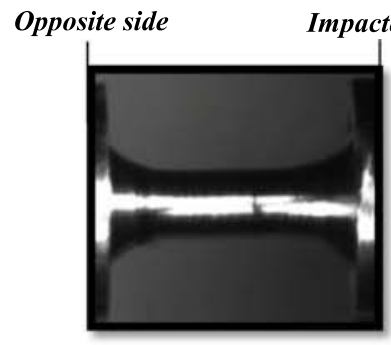

(a)
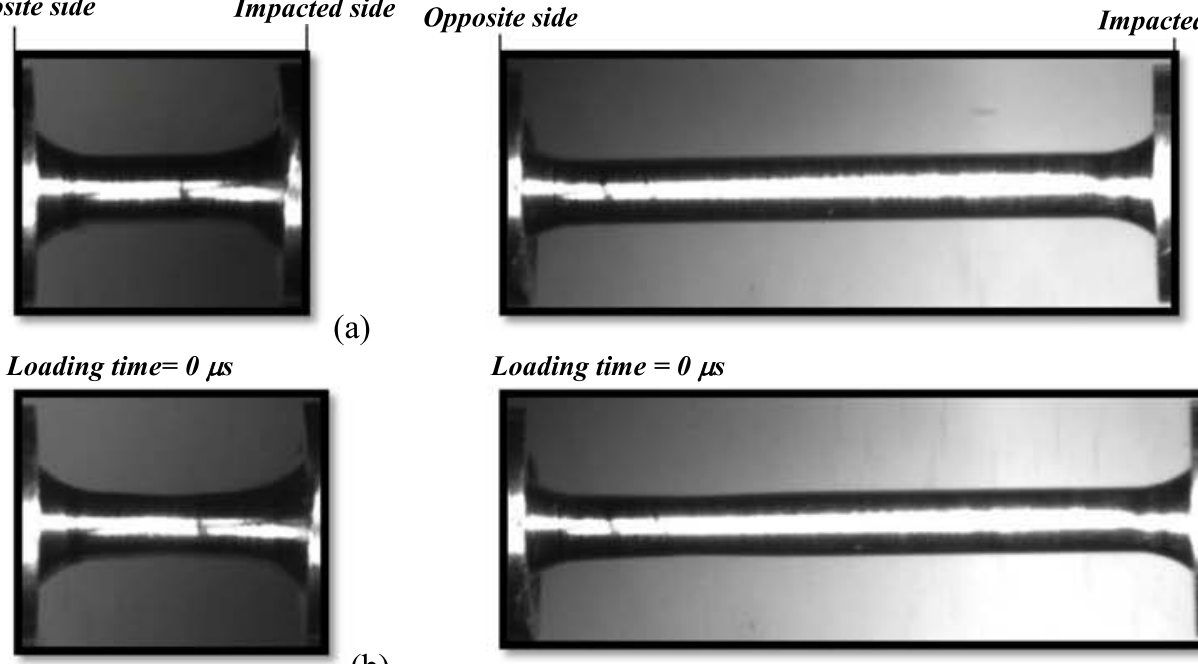

Loading time $=0 \mu \mathrm{s}$

(a)

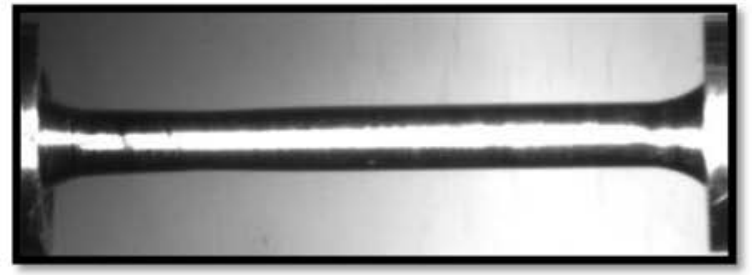

(b)

Loading time $=29 \mu \mathrm{s}$

Loading time $=96 \mu \mathrm{s}$

(b)
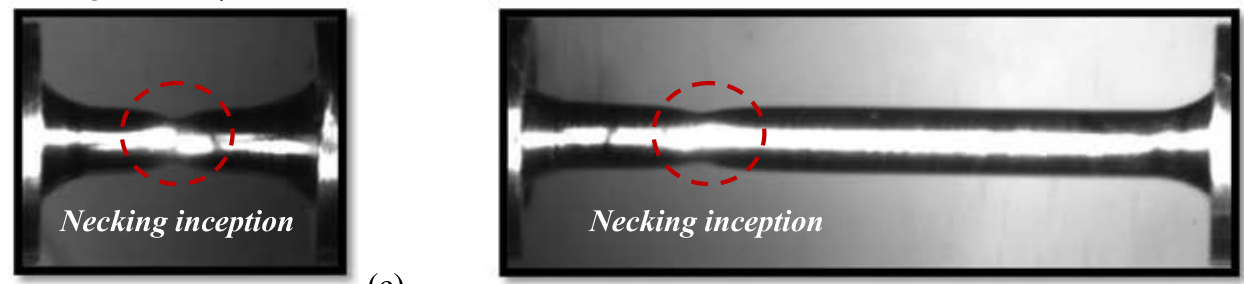

(c)

Loading time $=59 \mu \mathrm{s}$

Loading time $=132 \mu \mathrm{s}$
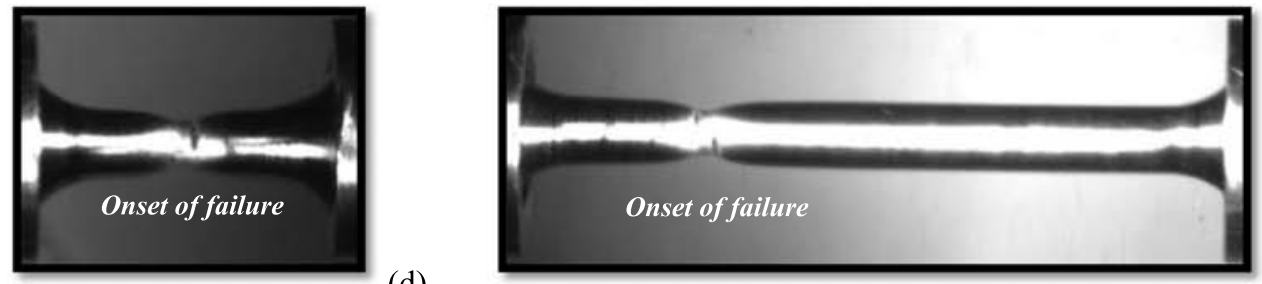

(d)

Loading time $=69 \mu \mathrm{s}$

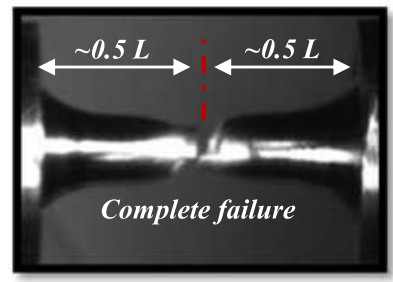

Loading time $=88 \mu \mathrm{s}$

(e)
Loading time $=151 \mu \mathrm{s}$

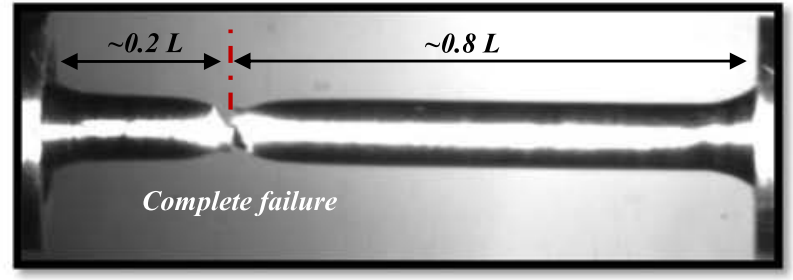

Loading time $=170 \mu \mathrm{s}$ (c)

(d)

(e)

Fig. 5. High speed photographic recording of the tensile deformation process. Left: specimen $3(L=7 \mathrm{~mm})$. Right: $\operatorname{specimen} 6(L=30 \mathrm{~mm})$. The impact is applied on the right handside of the specimens. (a) The specimens are at rest. (b) Uniform elongation phase. (c) Neck inception. (d) First frame where fracture is observed. (e) First frame where complete failure is observed. Note that while the neck develops in the middle of the shorter specimen, its location for the longer one is close to the opposite side.

ditions. Three types of conditions were used, all of which match the experimentally measured strain-rate:

1. Experimental boundary conditions: The applied velocities are those measured in the dynamic tensile experiment to be modeled. An example of such velocity profiles is shown in Fig. 8(a).
2. Encastrated: The specimen is clamped at one end, and a constant velocity that causes a strain rate equivalent to that measured, is applied at the other end, as shown in Fig. 8(b). Here, the velocity was applied with a rise-time of $12 \mu \mathrm{s}$ to match experimental conditions. 


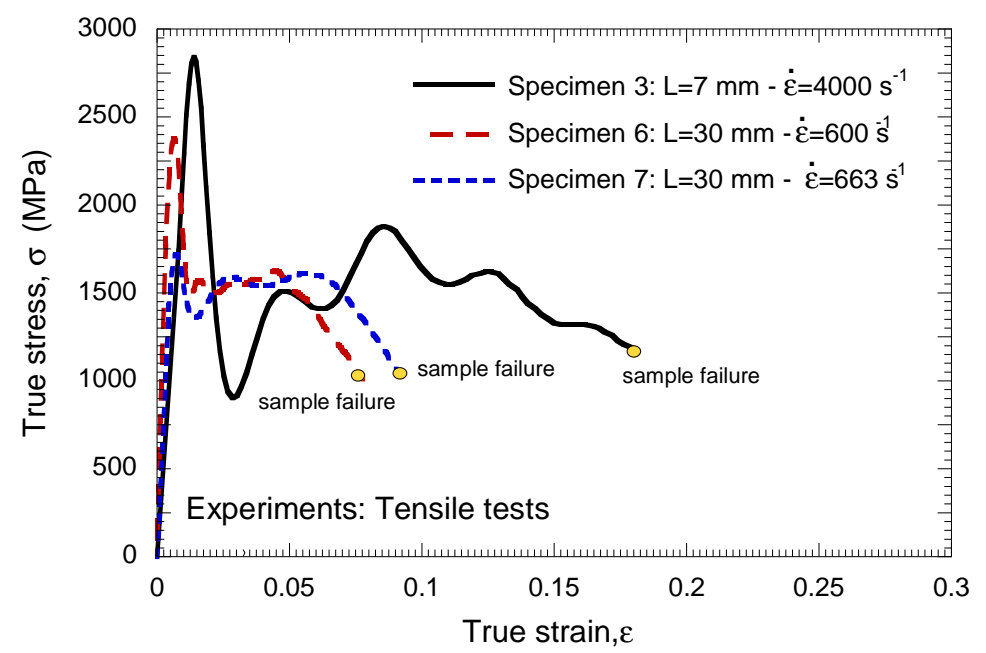

Fig. 6. Dynamic tensile true stress-strain curves for specimens 3,6 and 7. Note the relative lack of strain-rate sensitivity.

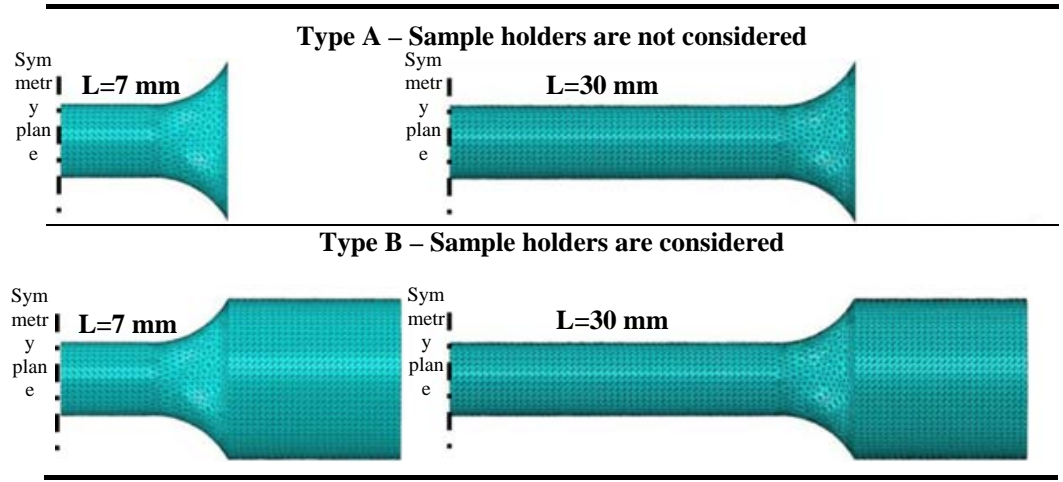

Fig. 7. Meshed specimens with 7 and $30 \mathrm{~mm}$ gauge length for type A and type B FE models.

3. Experimental velocities synchronized: A velocity profile identical to that mentioned in point 1 was used, with the difference that instead of being delayed by a few microseconds as a result of wave transfer through a finite length specimen, both incident and transmitted velocities were now synchronized as shown in Fig. 8(c).

Since the simulations were aimed at replicating actual experiments, no specific failure criterion was used here, and instead, the reference frames were taken from the experiment itself, as to the onset and various development stages of the neck, as well as final specimen fracture.

\section{Numerical simulations results}

We simulated the dynamic response for each specimen under the 3 BC's mentioned in the previous section. Fig. 9 shows the comparison between experiments (constitutive description implemented into the FE code to define the material behavior) and numerical simulation results obtained using the experimental boundary conditions for specimens
1 and 6. This figure shows that the range of strains over which the stress-strain behavior obtained from the numerical computations and the material constitutive description coincide, is by far more limited in the case of the longer specimen. In agreement with experiments, earlier necking of the longer specimen limits the range of attainable strains for proper material characterization. One should note that the various kinds of boundary conditions applied to the simulations hardly influenced the specimen response in terms of stress-strain characteristics.

However, it was observed that the boundary conditions strongly affect the necking strain and its exact location. To illustrate this point, one can analyze the local strain evolution in time in the vicinity of the neck. Fig. 10 shows the plastic strain distribution along the specimeńs gauge at (experimental) fracture time, for a short specimen (a specimen 3 ), a longer specimen (b - specimen 9 ), and another longer specimen (c - specimen 5). All the imposed strain rates were the experimentally determined ones.

All the results shown in each figure, for the 3 different boundary conditions, are obtained at the same time step, 

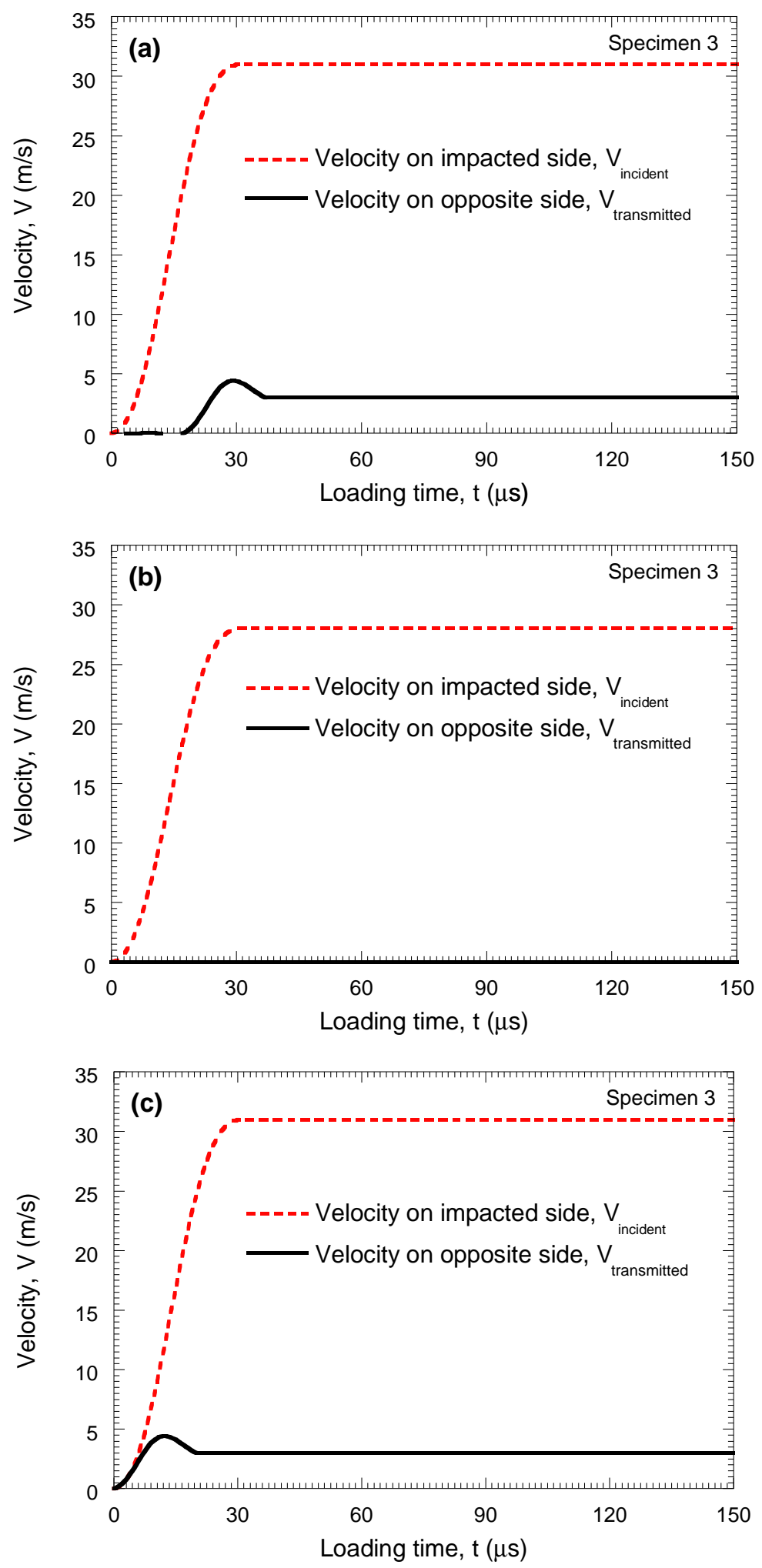

Fig. 8. Examples of velocity profiles used in the numerical simulations for specimen 3 . Dashed lines represent the velocity profile measured in the incident bar and the solid lines for the transmitted bar. (a) Experimental velocity profiles. (b) One side clamped. (c) Same as (a) but shifted in time to cause coincident velocity rises. 


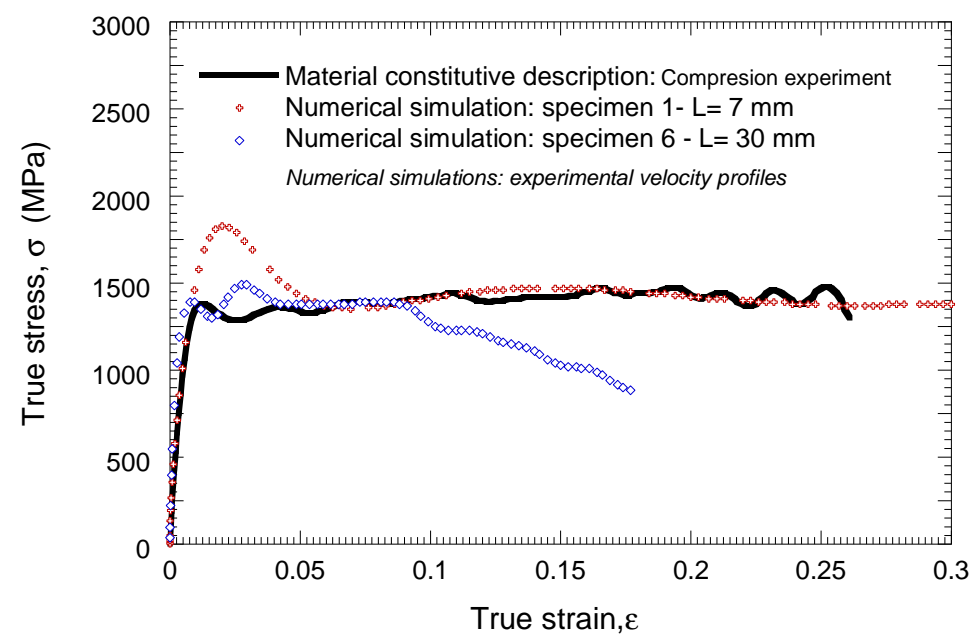

Fig. 9. Simulated true stress strain curves for (a) short specimen $(L=7 \mathrm{~mm}-$ specimen 1$)$ and (b) long specimen $(L=30 \mathrm{~mm}-\mathrm{specimen} 6)$. The experimental velocity profiles have been used in the simulations.

namely as close as possible to macroscopic fracture time (see experimental section). Those figures show unambiguously that, irrespective of the specimen's length, both the strain distribution and the location of the neck are strongly affected by the nature of the boundary conditions, remembering that the strain rate is kept identical in each investigated case. Even a small time shift in the applied velocities, such as in the case of the synchronized velocities, has a very noticeable effect. This figure also reveals an excellent agreement between the location of the calculated peak strain and the observed location of the experimental neck (Table 1) when the experimental boundary conditions are used. Another interesting observation from Fig. 10 is that, while the simulated and measured macroscopic stress-strain curves (Fig. 9) exhibit loss of stability at different macroscopic strains, the local failure strain is the same for all simulations regardless of the specimens' dimensions, again when experimental boundary conditions are used. Its value is of the order of 0.3 (Fig. 10) for the investigated material within the range of strain rates tested. Finally, this figure shows that the smallest discrepancy in neck position and local strain amplitude resulting from the three different boundary conditions is obtained for the shorter specimen.

Let us now examine the influence of the FE model itself - in which type A does not take into account the sample holders while type $B$ does - on the buildup of plastic strains in a dynamically stretched specimen. The goal is to compare the numerical results in terms of necking location depending on the type of FE element model used. For that task we will use the specimen $9(L=30 \mathrm{~mm})$ as an illustration. Fig. 11 displays the evolution of plastic strain with time along the gauge of the sample specimen simulated with the experimental B.C's for type A (Fig. 11(a)) and type B (Fig. 11(b)) FE models.

It can be observed that the plastic strain distribution along the sample gauge strongly depends on the FE element model considered, determining the necking location.
In the case of Fig. 11(b) (type B taking into account the sample holders) the necking location largely differs from the experimental one. This effect further emphasizes that necking location in a dynamically stretched sample is governed by wave disturbances. A simple change in the distance between the specimen's loaded surfaces (the value of $H$ varies with the FE model used: for type $A H=0 \mathrm{~mm}$; for type $B H=8 \mathrm{~mm}$ ) strongly affects the wave dynamics and therefore the strain localization process. Bearing in mind that the effect of wave propagation on sample straining is enhanced with increasing sample length, the boundary conditions will play a major role as the specimen gauge length increases.

\section{Discussion}

This paper presents a systematic investigation of the dynamic tensile response of a high strength steel, used here as a model material rather than a specific one. The interest of the study lies in the fact that the experiments and the simulations are highly coupled, in the sense that the experiments "drive" the numerical simulations, in a context for which very few experiments are usually carried out, while the available numerical or analytical work is not "backed-up" by actual experiments. The following points arise from this study.

Our experiments allow us to refine our understanding of the macroscopic (structural) and the local strain (material ductility). Usually those two concepts are tied together or even considered as identical, or eventually as a material property. Our observations show that the macroscopic strain is in fact a structural characteristic, which depends first and most of all on the geometry and size of the specimen. The development of a neck in the specimen, shortly followed by fracture, is observed to dictate the structural ductility. When comparing two specimens of different lengths and strain rates, so that the product of those quantities shows that the applied velocity was highly similar, 

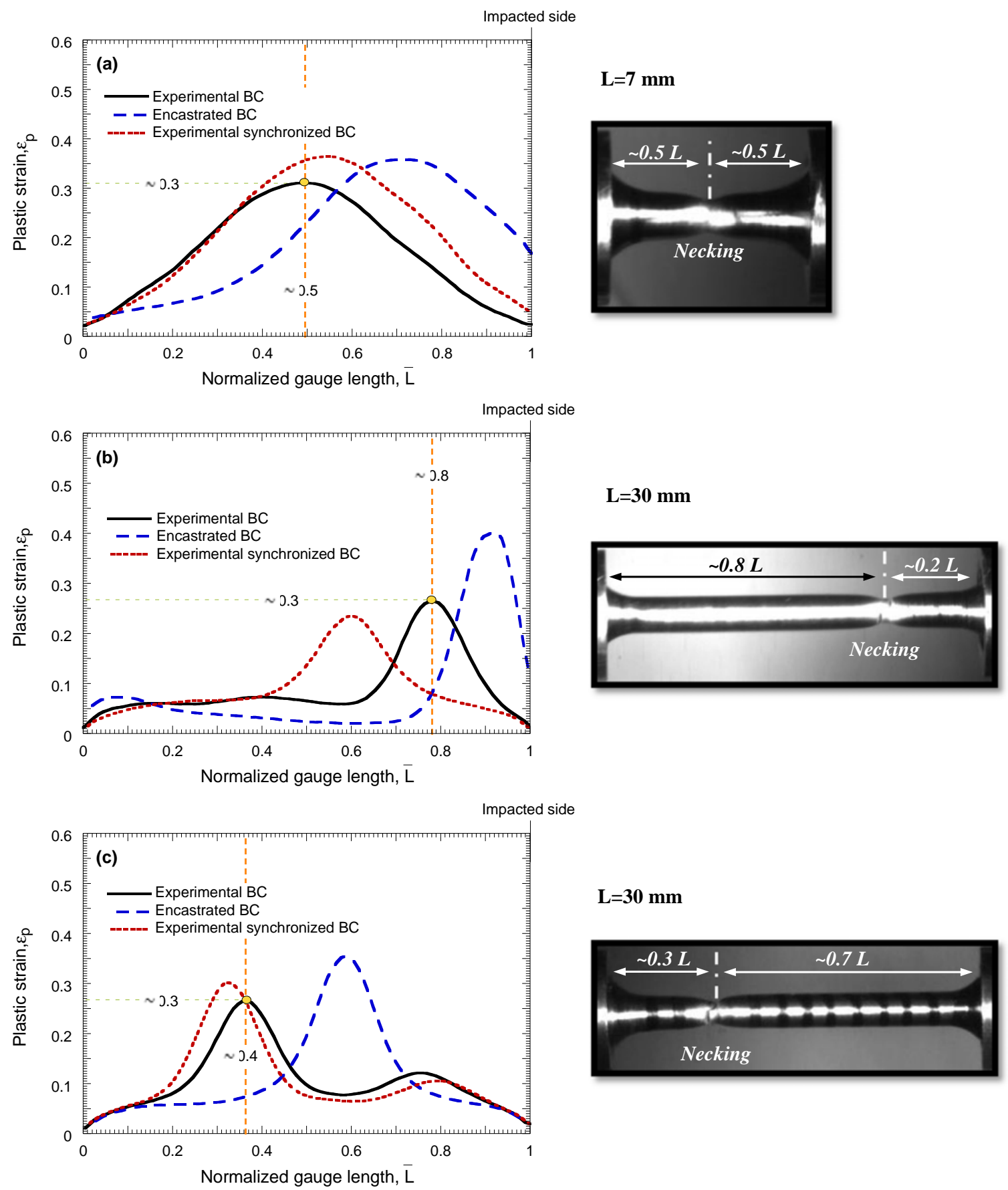

Fig. 10. Equivalent plastic strain distribution in (a) specimen 3, (b) specimen 9 and (c) specimen 5 . For each specimen, the three different types of boundary conditions were applied. The results are displayed at a time step that is very close to specimen fracture for each investigated case. Note the satisfactory agreement between the calculated peak strain and the experimentally recorded failure locus.

Table 1 reveals that the longer specimen fails at a smaller structural strain. While this observation bears no implication on a specific material property, it is nevertheless of interest for designers of impact loaded structures for which the dominant parameter is the impact velocity and the outcome of interest is the structural ductility to failure. Apparently, this geometrical influence in a low strain-rate sensitivity material may be ascribed to the importance of the waves' propagation which seems to be dominant in the long specimen. Hence, from a more practical point of 

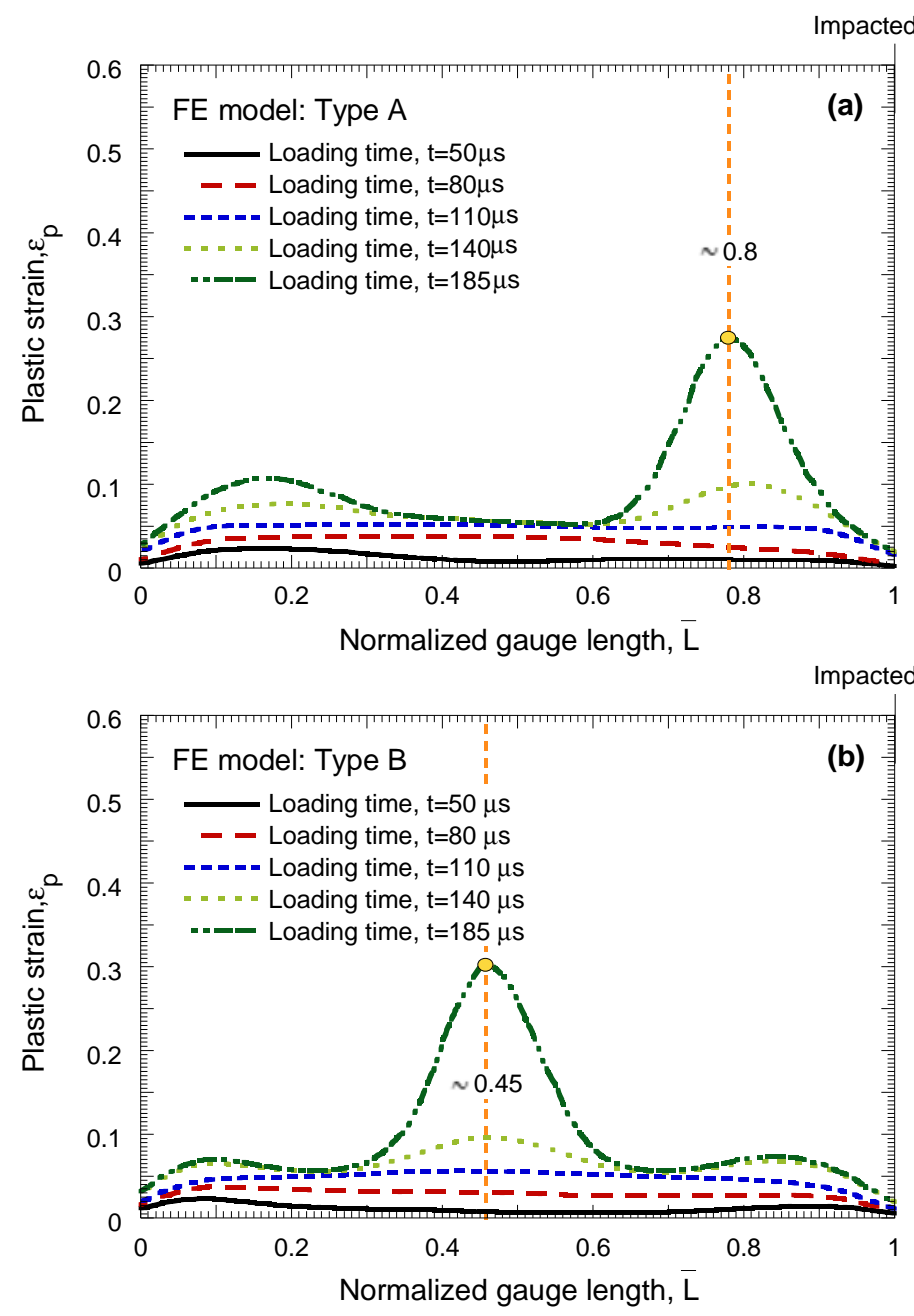

Fig. 11. Plastic strain buildup along the normalized gauge length in specimen 9 .

view, we suggest that by testing relatively short specimens, the reachable structural strain levels prior to neck formation are larger. This point is in total agreement with earlier analyses justifying the use of shorter specimens (Clark and Wood, 1950; Tanimura and Mimura, 2001; Rusinek et al., 2005).

The next point has not been previously reported or addressed, for the above-mentioned lack of coordinated experimental-numerical work on the subject. Namely, while boundary conditions are always open to some interpretation, the results of this work clearly reveal a strong influence of the definition of the boundary conditions on the nature of the calculated results (neck location and local strain). In a typical tensile Kolsky setup, the specimen cannot be considered as fully clamped on one side, as a first approximation. The existence of a small output velocity that is not synchronized with the input one, may significantly affect the location and the extent of the calculated peak strains in the specimen. This location in itself corresponds to the location of the incipient and fully formed neck. In that respect, the numerical calculations are in agreement with each simulated experiment, examples of which are found in Figs. 10 and 11. Having established this validation step of the numerical simulations, one can confidently consider the strain distribution along the specimen's gauge, as calculated with the actual experimental boundary conditions. The outcome of this exercise shows that, irrespective of the specimen's dimensions, the local strain at (close to) failure in the neck is remarkably constant, of the order of 0.3 for the investigated material within the range of strain rates tested. This constant local failure strain can be contrasted with the above-mentioned structural strain. Moreover, the experimentally calibrated numerical simulations clearly show that the location of the neck is fully deterministic, and thus predictable to a large extent, instead of being the result of the stochastic growth of a geometrical imperfection in the specimen. It is expected that advanced experimental techniques like the digital image correlation (Besnard et al., 2012) will shed additional light on the conditions leading to the onset 
of necking, the available information being confronted with numerical results of the kind reported in this work.

\section{Conclusions}

- Macroscopic (structural) and local ductility are distinct issues. The former is geometry dependent, while the latter was found to be constant for the investigated material. Both concepts are important, one for structural design, the second for material characterization.

- The use of short specimens is recommended but not mandatory, provided adequate numerical calculations are carried out along with the experiments.

- The nature of the applied boundary conditions is of utmost importance in modeling the strain distribution, local strain at failure and neck location in the specimen. The actual test boundary conditions should be used for optimal accuracy.

- The location of the neck is deterministic and can be simulated.

\section{Acknowledgements}

The researchers of the University Carlos III of Madridare indebted to the Comunidad Autónoma de Madrid (Project CCG10-UC3M/DPI-5596) and to the Ministerio de Ciencia e Innovación de España (Project DPI/2011-24068) for the financial support received which allowed conducting part of this work.

D. Rittel acknowledges the support of Carlos III University with a Catedra de Excelencia funded by Banco Santander during academic year 2011-2012.

\section{References}

Benallal, A., Berstad, T., Børvik, T., Hopperstad, O.S., Koutiri, I., Nogueira de Codes, R., 2008. An experimental and numerical investigation of the behaviour of AA5083 aluminium alloy in presence of the Portevin-Le Chatelier effect. International Journal of Plasticity 24, 1916-1945.

Besnard, G., Hild, F., Lagrange, J.M., Martinuzzi, P., Roux, S., 2012. Analysis of necking in high speed experiments by stereocorrelation. International Journal of Impact Engineering 49, 179-191.

Bottet, R., Rousseat, T., Gobin, P., 1969. A theoretical and experimental analysis of high strain-rate test using Malvern's theory. Journal of Applied Physics 2, 1235-1243.

Chiddister, J.L., Malvern, L.E., 1963. Compression-impact testing of aluminum at elevated temperatures. Experimental Mechanics 3, 8190.

Clark, D.S., Datwyler, G., 1938. Stress-strain relations under tension impact loading. Proceedings - American Society of Testing Materials $38,98$.

Clark, D.S., Duwez, P.E., 1948. Discussion of the forces acting in tension impact test of materials. Journal of Applied Mechanics 15, A243.

Clark, D.S., Duwez, P.S., 1950. The influence of strain rate of some tensile properties of steel. Proceedings - American Society for Testing Materials, 560-575.

Clark, D.S., Wood, D.S., 1950. The tensile impact properties of some metals and alloys transactions. American Society of Metals 42, 45.

Duwez, P.E., Clark, D.S., 1947. An experimental study of the propagation of plastic deformation under conditions of longitudinal impact. Proceedings - American Society of Testing Materials 47, 502.

Ehlers, S., 2010. The influence of the material relation on the accuracy of collision simulations. Marine Structures 23, 462-474.

Field, J., Walley, S., Proud, W., Goldrein, H., Siviour, C., 2004. Review of experimental techniques for high rate deformation and shock studies. International Journal of Impact Engineering 30, 725-775.
Hu, X., Daehn, G.S., 1996. Effect of velocity on flow localization in tension. Acta Materialia 44, 1021-1033.

Karagiozova, D., Mines, R., 2007. Impact of aircraft rubber tyre fragments on aluminium alloy plates: II-Numerical simulation using LS-DYNA. International Journal of Impact Engineering 34, 647-667.

Karman, T., 1942. On the propagation of plastic deformation in solids. NDRC Report No. A 29, February 2.

Karman, T., Duwez, P., 1950. The propagation of plastic deformation in solids. Journal of Applied Physics 21, 987.

Kazanci, Z., Bathe, K., 2012. Crushing and crashing of tubes with implicit time integration. International Journal of Impact Engineering 42, 80 88.

Klepaczko, J.R., 2005. Review on critical impact velocities in tension and shear. International Journal of Impact Engineering 32, 188-209.

Klepaczko, J.R., 2007. Introduction to Experimental Techniques for Material Testing at High Strain Rates. Warszawa Institute of Aviation Scientific Library, Warszawa.

Knoche, P., Needleman, A., 1993. The effect of size on the ductility of dynamically loaded tensile bars. European Journal of Mechanics A/ Solids 12, 586-601.

Lifshitz, J.M., Leber, H., 1994. Data processing in the split Hopkinson pressure bar tests. International Journal of Impact Engineering 15, 723.

Lindholm, U.S., 1974. Review of dynamic testing techniques and material behaviour. Proceedings of Conference on Mechanical Properties of Materials at High Rates of Strain. Institute of Physics, Oxford, pp. 3-21.

Manjoine, M.J., 1944. Influence of rate of strain and temperature on yield stress of mild steel. Journal of Applied Mechanics Transactions of the ASME 11, A-211.

Mann, H.C., 1936. High-velocity tension-impact tests. Proceedings ASTM $36,85$.

Mann, H.C., 1937. Fundamental study of the design of impact test specimens. Proceedings - American Society of Testing Materials 37, 102.

Miguélez, M.H., Zaera, R., Molinari, A., Cheriguene, R., Rusinek, A., 2009. Residual stresses in orthogonal cutting of metals: the effect of thermomechanical coupling parameters and of friction. Journal of Thermal Stresses 32, 269-289.

Parker, E.R., Ferguson, C., 1942. The effect of strain rate upon the tensile impact strength of some metals. Transactions, American Society for Metals 30, 68

Picu, R.C., 2004. A mechanism for the negative strain-rate sensitivity of dilute solid solutions. Acta Materialia 52, 3447-3458.

Rakhmatulin, H.A., 1945. Mechanics of unloading waves. Prikladnaya Matematika i Mekhanika 9, 91.

Rodríguez-Martínez, J.A., Rittel, D., Zaera, R., Osovski, S., in press. Finite element analysis of AISI 304 steel sheets subjected to dynamic tension: the effects of martensitic transformation and plastic strain development on flow localization. International Journal of Impact Engineering

Rusinek, A., Klepaczko, J.R., 1999. Comportement viscoplastique des toles en traction et cisaillement, analyse de la vitesse d'impact critique. Materiaux and Techniques 87, 41.

Rusinek, A., Klepaczko, J.R., 2003. Impact tension of sheet metals - effect of initial specimen length. In: Seventh International Conference on Mechanical and Physical Behaviour of Materials under Dynamic Loading, Oporto, Journal of Physique IV, vol. 10, pp. 329-334.

Rusinek, A., Zaera, R., Klepaczko, J.R., Cheriguene, R., 2005. Analysis of inertia and scale effects on dynamic neck formation during tension of sheet steel. Acta Materialia 53, 5387-5400.

Rusinek, A., Zaera, R., Forquin, P., Klepaczko, J.R., 2008. Effect of plastic deformation and boundary conditions combined with elastic wave propagation on the collapse site of a crash box. Thin-Walled Structures 46, 1143-1163.

Simmons, S.A., Hauserf, E., Dorn, J., 1961. In: Shewmon, R.G., Zackay, V.F. (Eds.), Response of Metals to High Velocity Deformation, 93. Interscience, New York, pp. 1-14.

Simulia, 2010. ABAQUS/Explicit User's Manual, Version 6.10 Edition, Dassault Systèmes, Providence, USA.

Tanimura, S., Mimura, K., 2001. Newly developed dynamic testing methods and dynamic strength of some structural materials. In: Akira Chiba, Tanimura, S., Hokamoto, K., (Eds.), Proceeding of the Fourth International Symposium on Impact Engineering Application, Kumamoto, Japan, vol. 1, pp. 57-64.

Vadillo, G., Rodríguez-Martínez, J.A., Fernández-Sáez, J., 2012. On the interplay between strain rate and strain rate sensitivity on flow localization in the dynamic expansion of ductile rings. International Journal of Solids and Structures 49, 481-491.

Varas, D., Zaera, R., López-Puente, J., 2009. Numerical modelling of the hydrodynamic ram phenomenon. International Journal of Impact Engineering 36, 363-374. 
Verleysen, P., Peirs, J., Slycken, J.V., Faes, K., Duchene, L., 2011. Effect of strain rate on the forming behaviour of sheet metals. Journal of Materials Processing Technology 211, 1457-1464.

Wang, L., Yang, L., Huang, D., Zhang, Z., Chen, G., 2008. An impact dynamics analysis on a new crashworthy device against ship-bridge collision. International Journal of Impact Engineering 35, 895-904.
White, M.P., Griffis, L., 1947. The permanent strain in a uniform bar due to longitudinal impact. Journal of Applied Mechanics, 337343.

Zhang, H., Ramesha, K.T., Chin, E.S.C., 2004. High strain rate response of aluminum 6092/B4C composites. Materials Science and Engineering A $384,26-34$. 